\title{
LE SINTHOME
}

Maria das Graças Leite Villela Dias

Psicanalista; doutora em Teoria Psicanalítica pelo Programa de Pósgraduação em Teoria Psicanalítica da UFRJ; professora do Departamento de Psicologia da Universidade Federal de São João del-Rei (UFS/MG).

RESUMO: Aborda-se a passagem efetuada por Lacan para a escrita topológica da nodal idade. Ao nó borromeano de três elos Lacan acrescenta um elo suplementar, le sinthome, definido em sua função de letra. Segundo ele, le sinthome é o que permite ao simbólico, ao imaginário e ao real ficarem juntos, graças a dois erros, dois pontos de falha estrutural que se produzem no enlaçamento do imaginário e do simbólico: o ponto do lapso, do equívoco fundamental, do nãosenso, onde se localiza o sintoma-metáfora; e o ponto da falta primordial, onde se situa lesinthome, em sua função de gozo e de suplência da fal ta.

Palavras-chave: Ponto do lapso; ponto da falta primordial; sintomametáfora; le sinthome.

ABSTRACT: Le sinthome. This work deals with Lacan's turn to the topological writings of nodality. To the Borromean knot of three rings Lacan adds a supplementary ring, le sinthome, defined in its function as a letter. According to it, it is lesinthomew hich permits the symbolic, the imaginary and the real to stay together, due to two errors, two points in the structural fault which are produced in the intertwining of the imaginary and the symbolic: the point of the lapse, the fundamental mistake, the no-sense, where the symptom-metaphor lies; and the point of the primordial fault, where le sinthome lies in its function of enjoyment and fault supplementation.

Keywords: Point of the lapse; point of the primordial fault; symptommetaphor; lesinthome.

ste artigo focaliza textos de Jacques Lacan, da década de 1970 - sobretudo R.S.I. (1974-1975/ s.d.) e Le sinthome (1975-1976/2005) — , momento em que, visando situar e apresentar materialmente a dimensão do real, Lacan recorre à escrita topológica da nodalidade na tentativa de demonstrar a consequêencia lógica do enlaçamento dos registros do real, do 
simbólico e do imaginário; em outras palavras, Lacan recorre à topologia do nó borromeano, buscando situar, através da figuração do real, o ponto central próprio à sua estrutura, ponto nodal mínimo, ponto do objeto a, núcleo real de gozo, situado no cerne do sinthome.

Em seu segundo Discurso de Roma, "La tercera" (1975/ 1985), Lacan, pela primeira vez, define o sintoma como "o que vem do real" (p.84). Segundo ele, "o sentido do sintoma não é aquele com que se o nutre para sua proliferação ou sua extinção, o sentido do sintoma é o real, o real enquanto se põe em cruz para impedir que as coisas andem, que andem no sentido de dar conta de si mesmas de maneira satisfatória" (p.81). Retoma, então, a tese, sustentada desde o início de seu ensino, de que "o real é o que volta sempre ao mesmo lugar" (p.81), acrescentando aqui que este lugar é o lugar do semblante. 0 objeto a, "núcleo elaborável do gozo" (p.90), na função de mais-de-gozar, é a condição do gozo, seja qual for: "todo gozo está conectado com estelugar do mais-de-gozar" (p.103).

A partir da teoria matemática dos nós, Lacan inventa uma escritura que lhe permite não só situar o real, mas apresentá-lo materialmente, em termos lógicos. Para tal, efetua uma passagem da escritura das superfícies (o toro e seu reviramento) - utilizada em seu seminário sobre La identificacion ( LACAN, 19611962/ 1986), escritura essa que supõe um real - para a escritura dos nós, que suporta um real. 0 recurso à topologia dos nós, referência enigmática à psicanálise, se dá na tentativa de figurar o espaço em suas três dimensões, superando, assim, a insuficiência do imaginário e os efeitos da binariedade especular e permitindo sair da impossível reciprocidade entre sujeito e objeto causa do desejo.

A escrita borromeana, utilizada por Lacan a partir de 1972, permite traduzir a trilogia "Simbólico, Imaginário e Real", ${ }^{1}$ introduzida por ele no início dos anos 1950, em termos de "Real, Simbólico e Imaginário" (R.S.I.), em função da primazia do real em relação aos dois outros registros. Essa primazia decorre do acento dado por ele ao real, no final de sua obra, o que o conduz à escolha da teoria dos nós, para além do modelo imaginário, como sendo a escritura que suporta um real, que é de estrutura. 0 nó borromeano é a forma de enlaçamento encontrada por Lacan para escrever a medida comum aos termos real, simbólico e imaginário.

Reproduzimos, neste texto, a figura planificada do nó borromeano² de três elos, conforme apresentada no seminário R.S.I. (LACAN, 1974-1975/ s.d.) . Cada

\footnotetext{
${ }^{1}$ Com a trilogia "Simbólico, Imaginário e Real" , Lacan, de certa forma, antecipa a articulação entre os três registros: "é na dimensão do ser que se situa a tripartição do simbólico, do imaginário e do real, categorias elementares sem as quais não podemos distinguir nada na nossa experiência" (LACAN, 1953-1954/ 1979, p.308).

${ }^{2}$ Quadros auxiliares ao seminário: quadro 8, figura I (acrescentamos: $S_{1}, S(\mathbb{A}$ ), corpo e oS pontos de falha).
} 
um dos círculos, por ser colorido, permanece identificado consigo mesmo e diferenciado dos demais. Nesse nó, “cada círculo passa por cima de um segundo círculo e por debaixo de um terceiro, mas esse terceiro tem a particularidade de passar, ele próprio, por baixo do segundo, o que constitui o encaixe próprio ao nó borromeano” (DARMON, 1994, p.228). Há, conforme a orientação, dois tipos desse nó: destrógiro e levógiro. No nó que reproduzimos, o nó levógiro, o círculo do real passa por cima do círculo do simbólico.

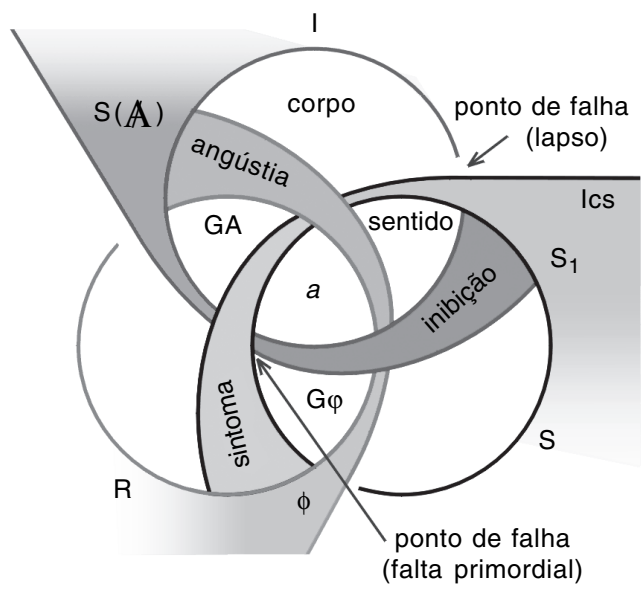

O nó borromeano se apresenta sob a forma de, no mínimo, três elos distintos, que se sustentam, cada um, pela suposta consistência real de corda. Há necessidade de uma certa matéria para que haja consistência. O suporte material dado por Lacan à consistência dos elos é a corda. Os elos são ligados e mantidos juntos apenas pela materialidade real de seu enlace. Cortando-se um dos elos, não importa qual deles, todos imediatamente se soltam e o nó se desfaz. Para Lacan, "essa propriedade, sozinha, homogeneíza tudo o que há de número a partir de três, o que quer dizer que, na seqüência dos números, números inteiros, um e dois são destacados, e alguma coisa começa no três, que inclui todos os números (...) É sempre de três que ele [o nó] trará a marca” (LACAN, 19741975 /s.d., p.6).

No seminário sobre Le sinthome (1975-1976/2005), Lacan diz que "os três círculos participam do imaginário enquanto que consistência, do simbólico enquanto que buraco e do real enquanto que ex-siste a eles" (p.56). A consistência, em sua materialidade de corda e em seu estatuto imaginário, é necessária para que o nó borromeano seja — e seja a partir de três. O imaginário dá consistência aos elos do nó, e a consistência dos elos só se suporta pelo real do nó.

Por sua vez, “a ex-sistência como tal, define-se, suporta-se disso que em cada um dos termos R.S.I. faz buraco” (LACAN, 1974-1975/s.d., p.12). Para que 
a ex-sistência seja real, "há uma só condição (...) é preciso para isso que ela tenha um buraco" (p.30). É em torno desse buraco que se sugere a ex-sistência. Há sempre, para dois dos três elos, um terceiro que realiza a nodulação e que, na sua função, ex-siste aos outros dois, apesar de sua presença ser necessária aos dois como ponto de apoio, de nodulação. Quanto ao buraco, ele é assegurado pelo simbólico, no tanto em que o significante faz buraco. Conforme Lacan, "o Simbólico gira em torno de um buraco inviolável, sem o que o nó dos três não seria borromeano" (p.46). 0 simbólico consiste no buraco que faz, buraco seguro, inviolável, que traz a marca do recalcamento primordial, irredutível e inacessível, em torno do qual gira.

De acordo com Lacan, "essas três palavras, Real, Simbólico e Imaginário, têm um sentido. São três sentidos diferentes (...) [com] uma medida comum" (LACAN, 19741975/ s.d., p.3, grifos nossos). São três termos com sentidos diferentes, sentidos estes que os distinguem cada um dos demais. Se a suposta consistência real de corda homogeneíza os elos, o sentido é o que os diferencia. E mais, "todos esses sentidos se referem ao Real, ao Real pelo qual cada um responde" (p.20).

Pela planificação do nó borromeano é possível uma figuração do real e do ponto central próprio à sua estrutura, ponto do objeto a, que conjuga três superfícies que igual mente se cruzam e que " permite acrescentar aí três outros pontos, algo que, em se definindo, traz-nos gozo" (LACAN, 1974-1975/ s.d., p.7). 0 real, no ponto triplo do cruzamento dos três elos, é a medida comum, que torna equivalentes três consistências com sentidos distintos, por estarem atadas em nó. 0 objeto a, objeto impossível e inatingível, vem alojar-se no encaixe central dos três elos, onde o buraco de um conjuga-se triplamente ao buraco dos outros dois, fixando o vazio da sua ausência. Tal como mostra o esquema do nó borromeano, o buraco central permite situar três campos de ex-sistência: 0 sentido, o gozo fálico e o gozo do Outro.

No buraco que o simbólico faz por sua intervenção no imaginário, buraco este que ex-siste frente ao real, Lacan escreve o sentido. 0 imaginário, cujo ponto de partida é a referência ao corpo, ${ }^{3}$ é 0 suporte do sentido. A relação que 0 sentido tem com o círculo consistente do real é, em princípio, de exterioridade. 0 real é o que escapa ao simbólico e ao imaginário, o que se situa mais além, 0 que ex-siste. No real, o sentido é reduzido ao objeto a, ponto nodal mínimo, ponto defascinação, ponto triplo, que toca igualmente os campos do gozo fálico e do gozo do Outro. É o sentido enquanto evanescente, o não-senso, o equívoco fundamental, $\mathrm{S}_{1}$, que dá consistência ao real. Enfim, o jogo simbólico não consiste

\footnotetext{
${ }^{3}$ Segundo Lacan, a forma do corpo "só mostra o saco, ou melhor, a bolha (...) pela existência e pela consistência que tem o corpo, de ser pele. Esta ex-sistência e esta consistência, é preciso tê-las como reais" ( LACAN, 1975-1976/ 2005, p.18).
} 
apenas em deslizar sobre o imaginário para produzir sentido, pois há um real implicado no nó, ponto de fixidez.

O gozo fálico se especifica pela interseção dos campos do real e do simbólico e pela sua ligação ao imaginário como ex-sistência. A intervenção do terceiro campo, o imaginário, situa o ponto cuja delimitação central define o lugar do objeto a. De acordo com Lacan, "é o gozo enquanto fálico que implica sua ligação ao Imaginá rio como ex-sistência; o Imaginário éo não-gozo" (LACAN, 1974-1975/ s.d., p.52). É do gozo fálico que provém a falta fundamental que inscreve a não-relação sexual. O não-gozo, cuja referência éo falo enquanto elidido, valendo em sua ausência, dá consistência ao imaginário. É no que o gozo fálico ex-siste ao imaginário que está 0 acento próprio do real. Lacan inscreve o gozo fálico, gozo que interessa ao Outro do significante, como balança ao que é do sentido. É no que há uma ligação da castração com o interdito do incesto que podemos dizer que não há relação sexual. A interdição do incesto é estrutural porque consiste no buraco do simbólico, buraco onde se aloja o Nome do Pai, onde se dá o sentido.

Por sua vez, o gozo do Outro, gozo que interessa ao Outro do corpo, ao Outro sexo, que não existe, situa-se na junção do real com o imaginário, fazendo frente ao simbólico, como ex-sistindo a ele. Segundo Lacan, “ para o Simbólico, é muito precisamente não haver Outro do Outro que Ihe dá consistência" (19741975/ s.d., p.52). Em “La tercera” (1975/ 1985), Lacan diz que "assim como o gozo fálico está fora-do-corpo, na mesma medida o gozo do Outro está fora-dalinguagem, fora-do-simbólico" (p.106). 0 ser humano é parassexuado, ${ }^{4}$ ou seja, entre o fora- do-corpo do gozo fálico e o gozo do O utro que está fora-da-linguagem, fora- do- simbólico, nada pode se passar, não há relação sexual, cada um fica no seu lado, fica ao lado do outro.

No seminário R.S.I. (1974-1975/ s.d.), Lacan acrescenta à trilogia um quarto elo, introduzindo o nó borromeano de quatro elementos, tipo especial de nó que parte da suposição "de uma disjunção concebida como originária do Simbólico, do Imaginário e do Real" (p.31). 0 atamento dos três registros supõe a ação suplementar de um elo a mais, indispensável para que os três se mantenham enlaçados.

No nó borromeano de quatro, cortando-se um só dos elos, não qual quer um, mas o último, cada um dos outros se libertará do seu seguinte, até o primeiro. Mas "deve-se fazer aí uma distinção, eles não se liberarão juntos, liberar-se-ão um após o outro" (p.47). Portanto, "é o último que mantém toda a cadeia" ( p.14). Ao suprimi-lo, não há mais cadeia. Para Lacan, “aí se especifica a função deste mais um como tal, é esse mais um que faz que suprimam-no, por exemplo, e não haverá mais cadeia, não haverá mais série, já que do fato apenas da secção desse um entre outros, todos os outros, digamos, se libertam como um" (p.14).

${ }^{4} 0$ prefixo para, do grego pará, significa ao lado de, que cada um permaneça ao lado do outro. 
Em Le sinthome (1975-1976/ 2005), Lacan prossegue: “parece que o mínimo que se pode esperar da cadeia borromeana é esta relação de um com três outros (...) é sempre em três suportes que chamaremos no momento de subjetivos, quer dizer, pessoais, que um quarto se apoiará" (p.51-52). Embora o nó implique o três como indispensável, há necessidade de um quarto termo, sem o qual nada é posto em evidência. Para ele,

"será retirando uma [ rodela] real, que o grupo se desata. É preciso, para isso, que se possa retirar uma real para a prova de que o nó é borromeano e que estão ali as três consistências mínimas que o constituem. (...) o quatro é o que, neste anel duplo, suporta o simbólico daquilo por que ele é efetivamente feito, a saber, o Nome do Pai" (LACAN, 1974-1975/ s.d., p.65).

A necessidade do quarto elo se impõe, uma vez que, no nó com três anéis, mudando-se à vontade a ordem dos mesmos, não se sabe qual é o real, ou seja, aquele que faz o nó. Com quatro elos, uma distinção se impõe, definindo três tipos de enlaçamento.

O quarto elo éaquele cuja consistência Lacan atribui, de início, ao Nome do Pai em sua função radical de dar um nome às coisas e, em seguida, ao Nome do Pai no plural, como já havia anunciado antes. Os Nomes do Pai, sob três formas, nomeiam o imaginário, o simbólico e o real, que por sua vez suportam o nó, ou seja, o nó se suporta de três indicações diferentes de sentido, figuradas nas nominações do simbólico, do imaginário e do real. É na distinção dessas três nominações que Lacan encerra o seminário. De acordo com Darmon (1994), para chegar a esta distinção, no esquema do nó borromeano,

“é preciso considerar o encaixe de três semi planos, de três superfícies representando o desdobramento até 0 infinito de cada consistência, quando o círculo se transforma numa reta: é o campo varrido por esse desdobramento. A partir do encaixe das três superfícies, é preciso então admitir que as superfícies se interpenetrem, ou seja, 0 ponto de encaixe é ultrapassado e as superfícies se cruzam. Resulta dessa operação o desenho do nó borromeano com os cantos da inibição, do sintoma e da angústia." (p.263)

A inibição, nominação do imaginário, se produz no campo do simbólico como efeito do imaginário e constitui o laço entre o real e o simbólico; é exterior ao sentido e ao corpo; e dá sentido à natureza do gozo do Outro. Pela planificação do nó borromeano, constatamos que, no cruzamento do objeto a com 0 gozo do Outro, o que responde pela inibição, instalada no campo do simbólico, é a inexistência do Outro, S( ). 
A angústia, nominação do real, se produz no campo do imaginário - no corpo - como efeito do real e constitui o enlace do simbólico e do imaginário; é exterior ao gozo do Outro e ao real; e dá sentido à natureza do gozo fálico. Para Lacan, "a angústia é isso que, do interior do corpo, ex-siste quando há al guma coisa que o desperta, que o atormenta" (LACAN, 1974-1975/ s.d., p.13). No cruzamento do objeto a com o gozo fálico, é o Falo $(\Phi)$ que responde pela angústia. É na associação do corpo ao gozo fálico, onde $0 \Phi$ ex-siste, que a angústia ganha sentido.

O sintoma, nominação do simbólico, que constitui o laço entre o imaginário e o real, se produz no campo do real como efeito do simbólico; é exterior ao gozo fálico e ao simbólico; e dá sentido à natureza do sentido. É o sentido do sentido: "fina flor do próprio simbólico" (p.70). Apenas o nó da nominação do simbólico será reutilizado por Lacan como nó do sintoma, no tanto em que supõe a castração, mas também, ao mesmo tempo, a prescrição do sintoma.

A escrita borromeana permite demonstrar materialmente a existência de uma estrutura que se sustenta em um real irredutível ao simbólico, mas a ele ligado. Coloca-se, então, a questão da criação do sentido e de suas relações com o inconsciente e o sintoma. 0 inconsciente pode agora ser situado em relação ao simbólico, ao imaginário e ao real, como o que ex-siste ao simbólico, e que é, portanto, necessário à nodulação do imaginário e do real, tal como o constata a produção do gozo do Outro, situado na junção desses dois registros. Como vimos, para o si mbólico, que ex-siste a esses dois registros, "é muito precisamente não haver Outro do Outro que Ihe dá consistência" (p.52). 0 inconsciente, implicado na nodulação do imaginário e do real, no ponto central do encaixe, revela a verdade de que não há Outro do Outro, verdade que veicula a impossibilidade da relação sexual.

No seminário R.S.I. (1974-1975/ s.d.), Lacan retoma o tema da identificação na tentativa de demonstrar a articulação desta com a função de nodulação do Nome do Pai. Para tal, parte da noção de identificação tripla, desenvolvida por Freud em "Psicologia das massas e análise do eu" (FREUD, 1920/ 1980), e amplamente elaborada por ele em 1962, no seminário com esse título. De acordo com Lacan:

“se há um Outro Real, não está senão no próprio nó e é por isso que não há Outro do Outro. Esse Outro Real, identifiquem-se com o seu Imaginário, terão então a Identificação do histérico com o desejo do Outro, essa que se passa nesse ponto central. Identifiquem-se com o Simbólico do Outro Real, terão essa Identificação que especifiquei como Einziger Zug, como traço unário. Identifiquem-se com o Real do Outro Real, obterão o que indiquei como o Nome do Pai, e é onde Freud designa o que a identificação tem a ver com o amor" (LACAN, 1974-1975/ s.d., p.53). 
No ponto central do nó, onde se aloja o objeto a, Lacan situa a identificação ao Outro em suas três dimensões: imaginária, simbólica e real. No intuito de ilustrar a consistência desse ponto central, que conjuga os três registros em seu enodamento, dando-Ihes uma medida comum, recorre à figura do triskel, ${ }^{5}$ correlato daquilo que Freud nomeou como traço único e que foi renomeado por Lacan como traço unário, suporte da identificação minimalista, especificada aqui como sendo 0 que dá consistência ao buraco central. Para Lacan:

“Não se podia dizer melhor o que compõe o nó, não sem ter na cabeça não haver amor senão aquele que, do Nome do Pai, faz anel entre os três, faz anel dos três do triskel. (...) É enquanto o Nome do Pai é aqui o que faz nó, e em se tratando do triskel, o Nome do Pai, aqui, do triskel faz nó, é enquanto pois o triskel ex-siste que pode haver identificação, identificação a quê? Ao que em todo nó borromeano éo coração, o centro do nó (...) o lugar do objeto pequeno a" (LACAN, 1974-1975/ s.d., p.65).

0 sintoma é definido, nesse seminário, como função de letra, $f(x)$, um signo isolado da cadeia significante, uma cifra de gozo. 0 objeto a, resto de gozo inassimilável pela articulação significante é, portanto, o centro, o caroço do sintoma. 0 sintoma-letra, articulador do inconsciente e do gozo, define o "modo como cada um goza do Inconsciente, na medida que o Inconsciente o determina" (p.37). Ele é aquilo que, não cessando de se escrever, supre o que não cessa de não se escrever, isto é, a impossibilidade da relação sexual.

Se o sintoma é letra, letra de gozo e, nessa função, localiza-se no ponto central do nó, então, identificar-se com o objeto a significa identificar-se com 0 sintoma. Todo um é suscetível de se escrever com uma letra, e a letra, o que vem do real, é o que não cessa de se escrever no sintoma. Daí decorre 0 acento sobre 0 objeto, que fixa a fal ha significante $\left(S_{1}\right)$ onde se produz o sintoma; daí se deduz também que 0 amor diz respeito à função do pai, no tanto que ele é o portador da castração e da interdição do incesto.

No seminário sobre Le sinthome (LACAN, 1975-1976/ 2005), o quarto termo, aquele que estabelece a forma singular de um sujeito manter juntas essas três diferentes dimensões, será referido como sendo o sintoma. Presume-se que esse sintoma não deixa de ter relação com o Nome do Pai, vindo de alguma forma substituir o enfraquecimento da metáfora paterna, suprindo a carência paterna.

Nesse texto, Lacan adota a grafia sinthome, "forma antiga de escrever o que foi posteriormente escrito symptôme" (p.11), e fundamenta a distinção que faz recor-

\footnotetext{
5 "Três fuzis ensarilhados, que se suportam uns aos outros; foi o que, talvez saibam, eé daí que o nome foi tirado, os bretões tomaram como arma, as armas da Bretanha moderna" (LACAN, 1974-1975/ s.d., p.65).
} 
rendo à etimologia da palavra symptôme, onde ptôma, do grego, significa queda. Le symptôme, o sintoma, do qual se espera que caia durante a análise, não é o mesmo ao qual se refere Lacan com o termo le sinthome, da antiga grafia francesa, para designar aquilo que não cai, que se fixa em torno da falta primeira e particular e da necessidade de que esta não cesse, para que continuem sendo possíveis o gozo e o desejo.

Na conferência “Joyce le symptôme", proferida em 16 de junho de 1975, por ocasião da abertura do $5^{\circ}$ Simpósio Internacional James Joyce, e anexada ao seminário Lesinthome, Lacan afirma: "éno tanto em que o inconsciente seata ao sinthome, que éo que há de singular em cada indivíduo, que podemos dizer que Joyce, como ele escreveu em alguma parte, se identifica ao individual. Ele é aquele que se privilegia de ter estado no ponto extremo para encarnar nele o symptôme" (p.168).

Ainda no seminário em questão, Lacan prossegue: "o que pela primeira vez defini como sinthome é o que permite ao simbólico, ao imaginário e ao real ficarem juntos, mesmo que nenhum fique mais com o outro, isto graças a dois erros" (p.94), dois pontos de falha estrutural que se produzem no enlaçamento do imaginário e do simbólico (e que estão representados na figura reproduzida neste texto). Em um desses pontos de falha, o saber inconsciente, para obter 0 sentido, opera com o equívoco, o não-senso, fazendo uma sutura, uma costura entre o imaginário e o simbólico. Conforme Lacan, "quando fazemos esta costura, ao mesmo tempo fazemos outra, entre o que é o sintoma e o real" (p.73), que é a sutura que se faz no outro ponto de falha da junção do imaginário e do simbólico. Nesse ponto, é le sinthome - cifra do real, letra de gozo - que faz o enlace entre o imaginário, o simbólico e o real, mantendo-os juntos.

Esses dois pontos de fal ha são elaborados e desenvolvidos por Lacan no seminário Os quatro conceitos fundamentais da psicanálise (1964/ 1985), a partir das operações de alienação e separação. A al ienação e a separação, definidas como operações de causação do sujeito, se dão em dois tempos: o tempo do sujeito e o tempo do objeto, que se inscrevem na fórmula da fantasia, $(\$ \diamond$ a). Esta fórmula fixa 0 instante de conjunção disjuntiva entre o sujeito barrado (\$) e o objeto a, e remete a dois pontos de fal ha. 0 primeiro ponto, demarcado pela operação de al ienação, libera um sujeito reduzido a uma falta de significante, o sujeito desejante, que se constitui pelo recalcamento originário, pela queda do significante primordial, $\mathrm{S}_{1}$, reduzido a puro não-senso. Lacan reconhece aí o ponto de falha onde se dá a formação do inconsciente. 0 outro ponto de falha, intrínseco à operação de separação, decorre da perda do objeto primordial, e é aí que Lacan reconhece o que Freud denomina Ichspaltung ou divisão do sujeito.

Corrigir igualmente os dois erros, as duas fal has por meio de um sintoma, não conduz ao mesmo resultado. Corrigir com o sintoma-metáfora, na produção de sentido, através do saber inconsciente, não é o mesmo que corrigir com lesinthome, 
o sintomaletra, na produção do gozo. 0 que se produz com a intervenção do sintoma no ponto do lapso, do equívoco, é diferente do que se produz com sua intervenção no ponto da falta primordial. Corrigir a falha, no ponto do lapso, do equívoco, do não-senso, coloca o sintoma em série com as demais formações do inconsciente. Corrigir a fal ha, no ponto da falta primordial, situa o sintoma em sua função de gozo, de suplência da falta estrutural da relação sexual. 0 gozo da relação que não existe é substituído pelo do sintoma. 0 sintoma, nesse sentido, é um fato de estrutura, efeito da impossibilidade da relação sexual; é uma suplência, uma resposta particular ao não há relação sexual, o que resta do que se chama a relação sexual enquanto relação intersintomática.

Para concluir, fazemos alusão a duas passagens enigmáticas da elaboração lacaniana que, por sua complexidade, configuram um vasto campo de pesquisa. Por um lado, a planificação do nó borromeano de três el os permite demarcar três campos de ex-sistência: o campo do sentido, o campo do gozo fálico e o campo do gozo do Outro, campos estes que, no real, ponto central do objeto a, são reduzidos, respectivamente, ao não-senso, ao não-gozo e ao não-Outro. Por outro lado, o acréscimo de le sinthome (cifra de gozo), como elo suplementar à trilogia R.S.I., permite depreender três indicações diferentes de sentido, figuradas, respectivamente, nas nominações do imaginário, do simbólico e do real: a inibição, o sintoma e a angústia.

Essa elaboração, embora permaneça enigmática e campo aberto à pesquisa, tem sido útil como referencial teórico, abrindo vias de estudo acerca das vicissitudes da inibição, do sintoma e da angústia, na vida e na análise. Tal elaboração permite ainda elucidar questões relativas à passagem, no processo analítico, do sintoma ao sinthome: como se processa a passagem da decifração, via sintoma-metáfora, característica dos tempos iniciais da análise, à identificação ao sintoma-letra de gozo, característica do final de análise? Dito de outra forma, como se dá a passagem da decifração do sintoma, que permite declinar os significantes mestres que determinam e ordenam a vida do sujeito, à identificação com o sintoma, que permite ao sujeito assumir a inércia do sintoma e o modo particular de gozo? Como pensar os operadores lógicos do final de análise (destituição subjetiva, travessia da fantasia e identificação ao sintoma) à luz da teoria dos discursos e da teoria dos gozos? Tais são as questões que, no momento, norteiam nossos estudos. 


\section{REFERÊNCIAS}

DARMON, M. ( 1994) Ensaios sobrea topologia lacaniana. Porto Alegre: Artes M édicas.

FREUD, S. ( 1980) Edição standard brasileira das obras psicológicas completas de Sigmund Freud. Rio de Janeiro: Imago.

(1926) "Psicologia das massas e análise do eu", v. XIII, p.91-184.

LACAN, J. (1975/ 1985) "La tercera", in Intervenciones e textos. Buenos Aires: Manantial. . (1953-1954/ 1979) 0 seminário livro 1, Os escritos técnicos de Freud. Rio de Janeiro: Zahar.

(1961-1962/ 1986) Seminário La identificacion. Versión de la Escuela Freudiana de BuenosAires: Laprida. (1964/ 1985) 0 seminário livro 11, Os quatro concei tos fundamentais da psicanálise. Rio de Janeiro: Zahar.

. (1974-1975/ s.d.) R.S.I. 0 seminário. Versão anônima, em francês e português.

(1975-1976/2005) LeséminairelivreXXIII, Lesinthome Paris: Éditions du Seuil.

M aria das Graças LeiteVillela Dias

gvillela@ufsj.edu.br 